\title{
Brain SPECT in a patient with catatonia: Case report
}

Jeff Huarcaya-Victoria $^{1,2}{ }^{2}$ A. Podestá ${ }^{2}$, M. Caqui ${ }^{2}$

1 Universidad de San Martín de Porres, Facultad de Medicina, Centro de Investigación en Salud Pública. Lima, Perú.

2 Departamento de Psiquiatría, Servicio de Psiquiatría General, Hospital Nacional Guillermo Almenara Irigoyen. Lima, Perú.

\section{BACKGROUND}

Catatonia was originally described as a psychomotor disease by Karl Ludwig Kahlbaum in 1874. Initially it was considered as the motor manifestation of schizophrenia. However, during the last decades it has been documented a greater prevalence of catatonic symptoms in affective disorders.

\section{RESULTS}

In June 2015 he received his first psychiatric care. He referred feelings of sadness, with spontaneous crying, feelings of frustration, guilt and anhedonia. He was diagnosed with a moderate depressive disorder, starting sertraline and alprazolam, which showed an improvement in his mood.
We recently observed a renewed interest in this syndrome due to functional

neuroimaging techniques, as these could be useful in the study of the pathophysiology of catatonia.

\section{OBJECTIVES}

Describe the neuroimaging findings of Brain Single-Photon Emission Computed Tomography (SPECT) of a patient with catatonia.

\section{MATERIAL AND METHODS}

We report the case of a 49-year-old male patient, who presented severe depressive and catatonic symptoms simultaneously.

Catatonia would be associated
with possible dysfunction of the
frontal lobes. According to the
literature, the premotor and motor
cortex would be functionally altered
due to abnormalities in the
cortical GABAergic control, which
would also produce affective and
behavioral symptoms.

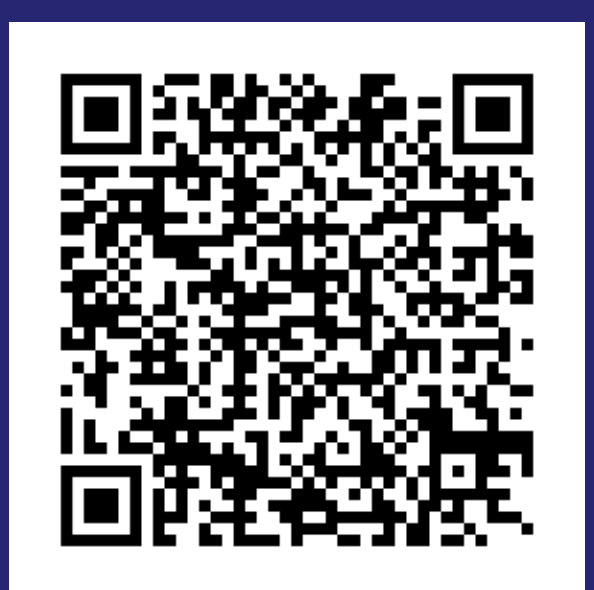
o download the full abstract
Take a picture
In June 2017, there was a psychomotor slowing and generalized stiffness, which generated difficulty feeding due to jaw stiffness, so they decided to take it to the emergency service.

Mental examination: Conscious, disoriented in time, blocking of thinking. Ecolalia and verbigerations. Blunted affect. Mutism with stupor, maintenance of strange postures, waxy flexibility.

Bush-Francis scale for catatonia: 42.

The patient was treated with diazepam at $40 \mathrm{mg} /$ day and venlafaxine $150 \mathrm{mg} /$ day.

Figure 1. Brain SPECT of the Patient. Signs of global decreased perfusion and in the frontal and parietal lobes of frontal predominance (dorsolateral, prefrontal orbitofrontal). Discrete greater perfusion in temporal lobes of left predominance. These findings are similar to those reported in other cases, where it is documented in studies of functional neuroimaging of catatonic patients: right inferior lateral prefrontal cortex hypoperfusion, right posterior parietal hypoperfusion, also left temporal hypoperfusion and asymmetric uptake in basal ganglia with left hypoperfusion (1-3).

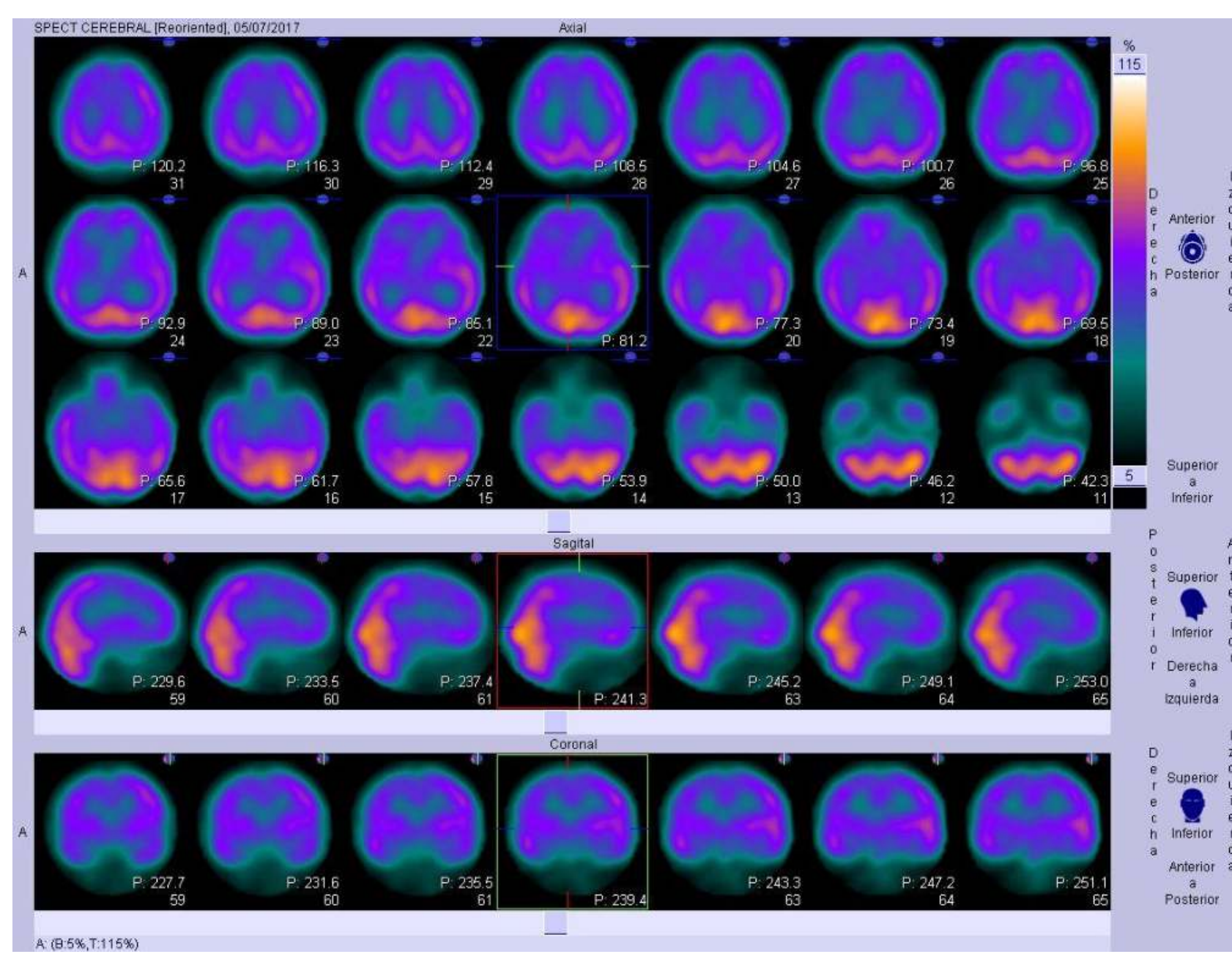

1. Mohandas E, Rajmohan V. Neural Correlates of Catatonia. Delhi Psychiatry Journal. 2008; 11(1): 59-63.

2. Bartolommei N, Lattanzi L, Callari A, Cosentino L, Luchini F, Mauri M. Catatonia: a critical Review and therapeutic recommendations. Journal of Psychopathology. 2012; 18: 234-246.

3. Northoff G. Catatonia and neuroleptic malignant syndrome: Psychopathology and Pathophysiology. J Neural Transm. 2002; 109: 1453-1467. 